\title{
George Sand et les arts, textes réunis par Marielle Vandekerkhove-Caors
}

\section{Lise Sabourin}

\section{(2) OpenEdition}

1 Journals

Édition électronique

URL : http://journals.openedition.org/studifrancesi/8979

DOI : 10.4000/studifrancesi.8979

ISSN : 2427-5856

Éditeur

Rosenberg \& Sellier

\section{Édition imprimée}

Date de publication : 1 octobre 2008

Pagination : 476-477

ISSN : 0039-2944

\section{Référence électronique}

Lise Sabourin, "George Sand et les arts, textes réunis par Marielle Vandekerkhove-Caors », Studi

Francesi [En ligne], 155 (LII | II) | 2008, mis en ligne le 30 novembre 2015, consulté le 10 janvier 2021.

URL : http://journals.openedition.org/studifrancesi/8979; DOI : https://doi.org/10.4000/studifrancesi. 8979

Ce document a été généré automatiquement le 10 janvier 2021.

\section{(c) (†)}

Studi Francesi è distribuita con Licenza Creative Commons Attribuzione - Non commerciale - Non opere derivate 4.0 Internazionale. 


\title{
George Sand et les arts, textes réunis par Marielle Vandekerkhove-Caors
}

\author{
Lise Sabourin
}

\section{RÉFÉRENCE}

George Sand et les arts, textes réunis par Marielle VANDEKERKHOVE-CAORS, Clermont-

Ferrand, Presses de l'Université Blaise Pascal, 2005 («Révolutions et romantismes», n.

5), pp. 230.

1 Ce volume collectif, issu du colloque tenu par le Centre de recherches révolutionnaires et romantiques au château d'Ars, tout près de Nohant, en 2004, s'intéresse à la relation qu'entretient George Sand avec la musique (pp.13-57), le théatre (pp.61-102), notamment de marionnettes (pp.103-150), mais aussi l'opéra et d'autres formes de spectacle (pp. 151-212).

2 Très sensible à la «musique naturelle» (Angélique Fulin, pp. 25-36), Sand, douée comme son père, formée par sa grand-mère, est initiée à la musique allemande par Planche, puis grâce à Liszt et Chopin. Elle s'est beaucoup intéressée à la collation des chants et danses populaires, berrichons tout autant que d'Europe centrale (Odette GONCET, Sand et les musiques d'Europe, pp.15-23). Elle a su trouver dans «la voix de contralto» (Liliane LAscoux, pp.37-49), une et multiple, douce et sensuelle, si typique de l'esthétique rossinienne et chère à Stendhal («El tanti palpiti»de Tancredi), incarnée dans sa génération par la Pasta, la Malibran et Pauline Viardot, une portée métaphorique due à sa profondeur de résonance androgyne, qui peut correspondre au sfumato pictural. Sa liaison avec Chopin (Irena PoniatowsKA, pp. 51-57) a été féconde - 46 pièces musicales pour lui, 21 ouvrages pour elle - car elle a su lui donner par son admiration l'équilibre si nécessaire à sa liberté créatrice, mais aussi parce que les deux artistes partageaient la tension entre l'ici et les espaces de l'imaginaire, essentielle à leur pensée sur la vie et la mort. 
Simone BERNARD-GRIFFITHS (pp. 61-78) décèle en la nouvelle La Marquise (1830) un des cas les plus représentatifs de l'importance de l'illusion théâtrale pour Sand: elle assure la cristallisation de la passion de l'héroïne pour l'acteur Lélio. Regina BOCHENEKFRACZAKOWA (pp. 79-90) démontre l'ambivalence générique non sans charme, entre mélodrame sentimental et comédie à réminiscences genlisiennes et moliéresques, des Mississipiens (1839) qui présente une intrigue typiquement sandienne - une épouse malheureuse quitte son mari en emmenant sa fille - placée par couleur locale en Louisiane au temps de Law. Bernard HAMON (pp. 91-102) retrace le succès public de l'adaptation théâtrale de son roman Le Marquis de Villemer et s'interroge sur l'absence de réactions des cléricaux, pourtant virulents peu auparavant contre Le Fils de Giboyer d'Augier, Gaetana d'Edmond About ou l'autre roman sandien de 1862, Mlle de La Quintinie. Il conclut, outre l'infléchissement de la politique impériale, plus libérale au vu de l'évolution du pouvoir temporel papal, à la reconnaissance par l'opinion des choix libres d'une artiste engagée.

4 Le théâtre de marionnettes, initié en 1846 à Nohant pour le piano de Chopin, inauguré en 1857 dans la salle construite par Maurice, occupe, on le sait, une part essentielle dans la créativité sandienne, banc d'essai de ses pièces, mais aussi approche de découverte pour ses romans. Françoise BALZARD-DORSEMAINE (pp. 119-124) fixe les étapes suivies par Maurice Sand dans la création de ses poupées, inspirées d'abord du mélodrame de boulevard, puis de la comédie italienne, enfin du "grand" théâtre et même de l'opéra. Joseph-Marc BAILBÉ (pp. 105-117) étudie comment le Stentarello florentin de la commedia dell'arte, si enrichi dans L'Homme de neige, fait du marionnettiste un artisan d'émotions collectives dont la fantaisie et la poésie permettent à Sand de poursuivre la mission d'éducation par le mythe qu'elle s'est fixée depuis 1840 en roman comme au théâtre. Pascale AURAIX-Jonchières (pp. 125-135) voit en Christian Waldo, «l'artisan-artiste» de L'Homme de neige, qui trouve dans le «château des étoiles» les signes de son intériorité d'errant, quasi bohémien, la quête toujours continuée du moi incertain. Le Diable aux champs qualifié par Sand de «comédie monstre», au sens d'objet fantastique et ludique (Marielle VANDKERKHOVE-CAORS, pp. 137-150), oscille entre roman et théâtralité: sur un prétexte d'intrigue sentimentale, les scènes regroupées en parties, les dialogue élargis de didascalies, les personnages d'animaux et de marionnettes proches de commedia dell'arte et du guignol, les caractères de la comédie de mœurs s'enchâssent pour châtier par le rire et contribuer au progrès social.

5 Se penchant sur l'univers romanesque de Sand, plusieurs articles y retrouvent l'influence de diverses formes de spectacle. Ileana Miraila (pp. 153-163) analyse, dans le diptyque essentiel de Consuelo et de La Comtesse de Rudolstadt, la reconstruction de la vie musicale au siècle des Lumières si cher à Sand, porteuse d'avenir progressiste tout autant que du souvenir de sa grand-mère: chanoine mélomane, musique populaire (quasi ethnologique), tragédie lyrique à la française, castrat et prima donna, Gluck et Métastase, Vénétie et Bohême s'entrelacent dans l'exaltation d'un idéal collectif grâce aux sensations esthétiques. Gérard CHALAYE (pp.165-181) insiste lui aussi sur la polyphonie artistique au service du récit qu'opère Le Château des désertes, relecture sandienne du mythe de Don Juan. Olga Kafanova (pp.183-197) note que La Dernière Aldini, le roman vénitien de 1838 si apprécié de Tourgueniev et Dostoïevski, voit sa diégèse et la typologie de ses héros déterminées par la musique, notamment le chant et la voix. Annabelle M. REA (pp. 199-212) enfin rapproche la danseuse et l'actrice, femmes 
dont le spectacle rend le corps visible, des défis et dangers que sait assumer la romancière dans la réalisation de sa vocation face aux coutumes de son temps.

6 Pour compléter cet éventail artistique, Claude Moins (pp. 215-225) compare le portrait de Sand par Delacroix, son voisin au quai Malaquais en 1834, qui sait fixer toute sa détresse après la rupture avec Musset, à celui, inachevé, qui la présente aux côtés de Chopin en 1838 dans l'instant douloureux de la création partagée. 